điêu trị dị dạng tĩnh mạch của chúng tôi đạt được kết quả tốt hơn.

Đối với dị dạng mạch máu dòng cao, Yakes và Do là hai tác giả nhiều kinh nghiệm đã chứng minh tính hiệu quả của cồn tuyệt đối, vật liệu gây xơ hoá mạnh và rẻ nhất. Theo báo cáo của Yakes, trong 20 trường hợp được điều trị can thiệp bằng cồn tuyệt đối, 7 trong số 11 bênh nhẩn bị dị dạng mạch máu lưu lượng cao có kết quả tốt, 4 trong số còn lại có thuyên giảm lưu lượng dòng chảy. Ngoài ra, trong nghiên cứu của Yakes, 7 trong số 9 bệnh nhân bị dị dạng mạch máu lưu lượng dòng thấp đạt kết quả thuyên tắc hoàn toàn ${ }^{2}$. Một nghiên cứu khác của Do, điều trị 40 bệnh nhân bị dị dạng mạch máu lưu lượng dòng cao, có 16 trường hợp được xem như điều trị khỏi hoàn toàn chiếm $40 \%$, thuyên giảm một phần chiếm $28 \%$, không thuyên giảm $18 \%$, $2 \%$ nặng thêm, và $12 \%$ thất bại điêu trị ${ }^{3}$. Khi so sánh kết quả của chúng tôi với kết quả của hai chuyên gia hàng đầu thế giới là Yakes và Do, kết quả điêu trị của hai tác giả có tỷ lệ thành công chữa khỏi hoàn toàn cao $63,63 \%$ theo Yakes, và $40 \%$ theo Do đối với dị dạng mạch máu lưu lượng dòng cao. Với nghiên cứu của chúng tôi, dị dạng mạch máu lưu lượng dòng cao chỉ chữa khỏi hoàn toàn về mặt hình ảnh học là 2 trong số 16 trường hợp. Ngoài hai tác giả nhiều kinh nghiệm trong việc sử dụng cồn tuyệt đối với tỷ lệ thành công và điều trị khỏi cao, biến chứng thấp, các nghiên cứu còn lại đều có kết quả tương đồng với nghiên cứu của chúng tôi ở hai phân nhóm dị dạng mạch máu dòng thấp và dị dạng mạch máu dòng cao.

\section{KẾT LUÂN}

Chẩn đoán hình ảnh bệnh lý dị dạng mạch máu ngoại biên đóng vai trò then chốt trong chẩn đoán xác định và phân loại dị dạng để có kế hoạch điều trị. Điều trị bằng cồn tuyệt đối chứng minh tính hiệu quả với tỷ lệ thành công, cải thiện triệu chứng lâm sàng và hình ảnh học cao. Tuy nhiên lý tưởng nhất vẫn là phối hợp nhiều phương pháp, trong đó điêu trị bằng can thiệp nội mạch với cồn tuyệt đối có thể xem như là điều trị đầu tay.

\section{TÀI LIỆU THAM KHẢO}

1. Lee Byung-B., Laredo J., Neville R. F., et al. (2015), "Epidemiology of vascular malformations", In: Hemangiomas and Vascular Malformations, Springer, pp. 165-169.

2. Yakes W. F. (2015), "Yakes' AVM classification system". Journal of Vascular and Interventional Radiology, 26 (2), pp. S224.

3. Do Y. S., Yakes W. F., Shin S. W., et al. (2005), "Ethanol embolization of arteriovenous malformations: interim results". Radiology, 235 (2), pp. 674-82.

4. Visser A., FitzJohn T., Tan S. T. (2011), "Surgical management of arteriovenous malformation". J Plast Reconstr Aesthet Surg, 64 (3), pp. 283-91.

5. Wang D., Su L., Han Y., et al. (2017), "Direct intralesional ethanol sclerotherapy of extensive venous malformations with oropharyngeal involvement after a temporary tracheotomy in the head and neck: Initial results". Head Neck, 39 (2), pp. 288-296.

\title{
KẾT QUẢ ĐIỀU TRI BƯỚC HAI PEMETREXED - CARBOPLATIN UNG THƯ PHỔI KHÔNG TÉ BÀO NHỎ SAU KHÁNG THỨ PHÁT THUỐC ỨC CHẾ TYROSINE KINASE
}

\section{TÓM TẮT}

Mục tiêu: Đánh giá kết quả điều trị của phác đồ Pemetrexed - Carboplatin trên bênh nhân ung thư phổi không tế bào nhỏ sau kháng thuốc ức chế Tyrosin Kinase (TKIs). Đối tượng và phương pháp: Hồi cứu 46 bệnh nhân sau kháng thứ phát EGFR TKIs,

\footnotetext{
*Bênh viện K Trung ương

**Bênh viên Hữu Nghi Hà Nôi

Chịu trách nhiệm chính: Nguyễn Thị Thái Hoà,

Email; bshoabvk@gmail.com

Ngày nhận bài: 3/3/2021

Ngày phản biện khoa học: 1/4/2021

Ngày duyệt bài: 2/5/2021
}

\section{Nguyễn Thị Thái Hoà', Mai Thanh Huyền ${ }^{2}$}

điều trị phác đồ Pemetrexed - Carboplatin, có theo dõi dọc. Kết quả: Tỷ lệ đáp ứng khách quan $50 \%$; đáp ứng hoàn toàn $0 \%$; kiểm soát bệnh 78,3\%. Các yếu tố tiên lượng đáp ứng kém: toàn trạng PS1, giai đoạn IV, di căn thần kinh trung ương. Sônng thêm khổng bệnh tiến triển trung vị : 4 tháng. Kết luận: Phác đồ Pemetrexed - Carboplatin là lựa chọn điều trị hợp lý cho bệnh nhân ung thư phổi không tế bào nhó sau kháng thuốc ức chế Tyrosin Kinase

Từ khoá: Ung thư phổi không tế bào nhỏ, kháng thuốc thứ phát, tỷ lệ đáp ứng, sống thêm không tiến triển.

\section{SUMMARY \\ TREATMENT RESULTS OF PEMETREXED- CARBOPLATIN REGIMEN AS SECOND-LINE}




\section{FOR NON-SMALL CELL LUNG CANCER AFTER EGFR TKIS ACCQUIRED RESISTANCE}

Objective: To evaluate the treatment results of Pemetrexed - Carboplatin regimen in patients with non-small cell lung cancer after Tyrosin Kinase inhibitor accquired resistance. Objects and methods: Retrospective of 46 patients after accquired resistance to EGFR TKIs, on Pemetrexed Carboplatin regimen, with longitudinal follow-up. Results: Rate of objective response $50 \%$; complete response $0 \%$; disease control $78.3 \%$. Prognostic factors for poorer response: performance status PS1, stage IV, CNS metastasis. Median progression - free survival: 4 months. Conclusion: Pemetrexed Carboplatin regimen is an appropriate treatment choice for patients with non-small cell lung cancer after resistance to Tyrosin Kinase inhibitors.

Keywords: Non-small cell Lung cancer, accquired resistance, response rate, progression- free survival.

\section{I. ĐĂT VẤN ĐỀ}

Điều trị ung thư phổi không tế bào nhỏ (UTPKTBN) giai đoạn tiến xa là điều trị toàn thân nhằm mục đích kéo dài thời gian sống, nâng cao chất lượng sống. Với những tiến bộ gần đây về điều trị nhắm đích, điều trị miễn dịch, kết quả điều trị nhóm bệnh nhân này đã phần nào cải thiện. Đột biến EGFR chiếm khoảng 30 - 40\% các bệnh nhân UTPKTBN tại Việt Nam [1]. Đột biến này thường xảy ra ở Exon 18-21, với hai đột biến phổ biến nhất là đột biến mất đoạn ở Exon 19 , và thay thế L858R ở exon 21. Đột biến T790M tại Exon 20 là đột biến kháng thuốc, thường xuất hiên ở khoảng $50-60 \%$ các trường hợp kháng thuốc thứ phát với TKI thế hệ 1 và 2 [2]. Với những bệnh nhân có đột biến kháng thuốc thứ phát, điều trị TKI thế hệ 3 cho hiệu quả vượt trội so với hóa trị bộ đôi [3]. Tuy nhiên, nhiều trường hợp không có đột biên này, hoặc không biết tình trạng đột biến, cũng như khổng có điều kiện điều trị TKI thế hệ 3 , hóa trị bộ đôi là một lựa chọn hợp lý cho phần lớn người bệnh.

Pemetrexed - Carboplatin là một trong những phác đồ tiêu chuẩn điều trị bước một ung thư phổi không tế bào nhỏ, không vảy giai đoạn tiến xa. Qua các dữ liệu nghiên cứu, phác đồ này cho hiệu quả cao, dung nạp tốt, đặc biệt thích hợp với bệnh nhân cao tuổi, bệnh nhân thể trạng yếu hoặc không dung nạp Cisplatin. Tuy nhiên, trên thể giới còn hiếm các đề tài đánh giá hiệu quả của phác đồ này trên bệnh nhân có đột biến EGFR, sau kháng thuốc ức chế EGFR Tyrosine Kinase

ở Việt Nam chưa có nghiên cứu nào đề cập vấn đè này, do vậy chúng tôi tiến hành đề tài nhằm mục tiêu: Đánh giá kêt quả điều trị của phác đồ Pemetrexed - Carboplatin trên bệnh nhân ung thư phổi không tế bào nhỏ sau kháng thuốc ức chế Tyrosin Kinase.

\section{II. ĐỐI TƯỢNG VÀ PHƯƠNG PHÁP NGHIÊN CỨU}

Bệnh nhân UTPKTBN giai đoạn IIIB, IV xác định tiến triển sau điều trị với TKIs, điều trị bằng phác đồ Pemetrexed - Carboplatin tại Bệnh viện $K$ và Bệnh viện Hữu Nghị từ 1/2017 - 8/2020.

\subsection{Tiêu chuẩn lựa chọn}

- Tuổi: từ 18 tuổi trở lên

- Giai đoạn IIIB, IV

- Mô bệnh học: ung thư biểu mô tuyến

- Kháng thứ phát sau điều trị bước 1 bằng

TKIs mà chưa nhận thêm điều trị nào khác

- Không có hoặc không biết tình trạng đột biến T790M sau kháng TKIs

2.2. Tiêu chuẩn loai trừ

- Không có dữ liệu để đánh giá đáp ứng

\subsection{Phương pháp nghiên cứu}

2.3.1. Thiết kế nghiên cứu: Nghiên cứu mô tả hồi cứu cắt ngang, có theo dõi dọc

2.3.2. Mẫu nghiên cứu: Lựa chọn cõ̃ mẫu thuận tiện.

\subsubsection{Phương pháp tiến hành}

Bệnh nhân điêu trị ít nhất 02 chu kỳ Pemetrexed - Carboplatin

+ Pemetrexed $500 \mathrm{mg} / \mathrm{m}^{2}$ truyên tĩnh mạch ngày 1

+ Carboplatin AUC 5-6 truyền tĩnh mạch ngày 1

+ Chu kỳ 21 ngày

Đánh giá đáp ứng theo tiêu chuẩn RECIST1.1 sau mỗi 2 chu kỳ

Đánh giá sống không tiến triển bệnh (PFS): là thời gian từ lúc bắt đầu điều trị đến khi bệnh tiến triển, hoặc tử vong hoặc kết thúc nghiên cứu tùy theo sự kiện nào đênn trước.

2.4. Xử lý số lieêuu. Số liệu được xử lý bằng phần mềm thống kể SPSS 16.0. Phân tích sống thêm theo phương pháp Kaplan-Meier.

2.5. Đạo đức trong nghiên cứu. Nghiên cứu tuân thủ đầy đủ các nguyên tắc đạo đức của nghiên cứu yhọc. Thông tin của BN được bảo mật.

\section{KẾT QUẢ NGHIÊN CỨU}

\section{1. Đăc điểm bệnh nhân}

Bảng 3.1. Bảng đặc điểm bệnh nhân

\begin{tabular}{|c|c|c|c|c|}
\hline \multicolumn{2}{|c|}{ Đặc điếm bệnh nhân } & $\mathbf{n}$ & $\%$ & Tống \\
\hline \multirow{2}{*}{$\begin{array}{c}\text { Nhóm } \\
\text { tuổi }\end{array}$} & $\geq 60$ & 22 & 47,8 & \multirow{2}{*}{46} \\
\hline & $<60$ & 24 & 52,2 & \\
\hline \multirow{2}{*}{ Giới } & Nam & 24 & 52,2 & \multirow{2}{*}{46} \\
\hline & Nữ & 22 & 47,8 & \\
\hline \multirow{2}{*}{ PS } & 0 & 35 & 76 & \multirow{2}{*}{46} \\
\hline & 1 & 11 & 24 & \\
\hline \multirow{2}{*}{$\begin{array}{c}\text { Giai } \\
\text { đoạn }\end{array}$} & IIIB & 13 & 28,2 & \multirow{2}{*}{46} \\
\hline & IV & 33 & 71,8 & \\
\hline
\end{tabular}




\begin{tabular}{|c|c|c|c|c|}
\hline Di căn & Có & 11 & 24 & \multirow{2}{*}{46} \\
\cline { 2 - 4 } não & Không & 35 & 76 & \\
\hline
\end{tabular}

Phần lớn các bênh nhân đều ở giai đoạn IV (71,73\%), các bệnh nhân còn lại ở giai đoạn IIIB $(28,27 \%)$.

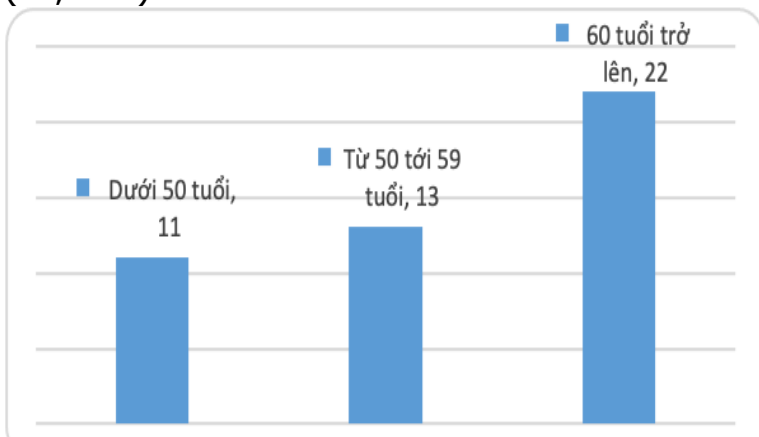

Biểu đồ 3.1. Phân bố theo nhóm tuổi

Tuổi trung bình: 57,3 土 9,0 năm, 39 - 77 tuổi

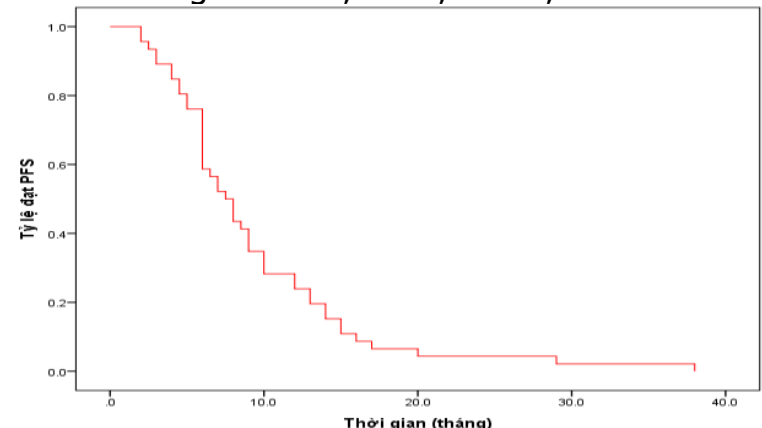

Biêu đđô 3.2. Thời gian sống thêm không tiến triến 1

Trung bình: 9,4 \pm 6,7 tháng (từ 2 tới 38 tháng)

Trung vị (tứ phân vị): 7,75 tháng (6 -12 tháng)

Nhận xét: Thời gian sống không bệnh tiến triển 1 trung vị là 7,75, ngắn nhất là 2 tháng, dài nhất là 38 tháng.
Phân lớn bệnh nhân có thời gian đáp ứng với TKI là trên 6 tháng

\subsection{Tỷ lệ đáp ứng}

Bảng 3.2. Tỷ lệ đáp ứng khách quan

\begin{tabular}{|c|c|c|}
\hline Loại đáp ứng & $\begin{array}{c}\text { Số bệnh } \\
\text { nhân }(\mathbf{n})\end{array}$ & $\begin{array}{c}\text { Tỷ lệ } \\
\mathbf{( \% )}\end{array}$ \\
\hline Hoàn toàn (CR) & 0 & $0,0 \%$ \\
\hline Một phần (PR) & 23 & $50,0 \%$ \\
\hline Bệnh ổn định (SD) & 13 & $28,3 \%$ \\
\hline Tiến triến (PD) & 10 & $21,7 \%$ \\
\hline Đáp ứng khách quan(ORR) & 23 & $50 \%$ \\
\hline Tỉ lệ kiểm soát bệnh(DCR) & 36 & $78,3 \%$ \\
\hline
\end{tabular}

Nhânn xét: Trong số 46 bệnh nhân nghiên cứu: không có bệnh nhân nào đáp ứng hoàn toàn (0\%), 23 bệnh nhân đạt đáp ứng một phân (50\%) và 13 bênh nhân bênh ổn định (28,3\%), có 10 bệnh nhân bệnh vẫn tiếp tục tiến triển (21,7\%). Như vậy, tổng đáp ứng khách quan (ORR) là 50,0\% và tỉ lệ kiểm soát bệnh (DCR) là 78,3\%.

3.3. Thời gian sống không bệnh tiến triển 2 (PFS2)

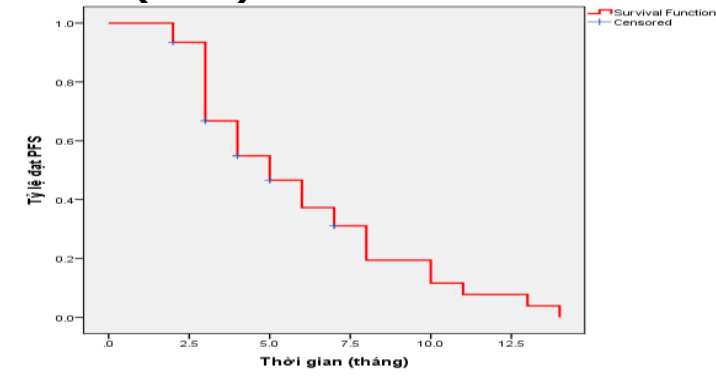

Biểu đồ 3.3. Biêu đồ thời gian sông không bệnh tiến triên 2

Trung bình 5,1 $\pm 2,9$ tháng (từ 2 đến 14 tháng) Trung vị (tứ phân vị): 4 tháng (3 - 6,75 tháng)

Bảng 3.3. Mối liên quan giữa tình trạng đáp ứng và đăc điêm của đôi tượng nghiên cứu

\begin{tabular}{|c|c|c|c|c|c|c|}
\hline \multirow{2}{*}{\multicolumn{2}{|c|}{ Yếu tố liên quan Tình trạng đáp ứng }} & \multicolumn{2}{|c|}{ Đáp ứng } & \multicolumn{2}{|c|}{ Không đáp ứng } & \multirow[t]{2}{*}{$\mathbf{p}$} \\
\hline & & $\mathbf{n}$ & $\%$ & $\mathbf{n}$ & $\%$ & \\
\hline \multirow{2}{*}{ Nhóm tuổi } & $\geq 60$ & 18 & 81,8 & 4 & 18,2 & \multirow{2}{*}{0,422} \\
\hline & $<60$ & 18 & 75,0 & 6 & 25,0 & \\
\hline \multirow{2}{*}{ Giới } & Nam & 19 & 79,2 & 5 & 20,8 & \multirow{2}{*}{0,578} \\
\hline & Nữ & 17 & 77,3 & 5 & 22,7 & \\
\hline \multirow{2}{*}{ PS } & 0 & 30 & 85,7 & 5 & 14,3 & \multirow{2}{*}{0,043} \\
\hline & 1 & 6 & 54,5 & 5 & 45,5 & \\
\hline \multirow{2}{*}{ Giai đoạn } & IIIB & 13 & 100,0 & 0 & 0,0 & \multirow{2}{*}{0,042} \\
\hline & IV & 23 & 69,7 & 10 & 30,3 & \\
\hline \multirow{2}{*}{ Di căn não } & Có & 3 & 27,3 & 8 & 72,7 & \multirow{2}{*}{$<0,001$} \\
\hline & Không & 33 & 94,3 & 2 & 5,7 & \\
\hline \multirow{2}{*}{ Loại đột biến } & 19del & 18 & 78,3 & 5 & 21,7 & \multirow{2}{*}{0,404} \\
\hline & L858R & 18 & 85,7 & 3 & 14,3 & \\
\hline \multirow{2}{*}{ Loại TKI điêuu trị bước 1} & Gefitinib & 6 & 85,7 & 1 & 14,3 & \multirow{2}{*}{0,543} \\
\hline & Erlotinib & 28 & 77,8 & 8 & 22,2 & \\
\hline
\end{tabular}


Nhân xét: Tình trạng đáp ứng có sư khác biệt có ý nghĩa thống kê đối với các đặc điểm chỉ số toàn trạng $(p=0,043)$, giai đoạn $(p=0,042)$ và tình trạng di căn não $(p<0,001)$, không có ý nghĩa thống kê đối với các đặc điểm nhóm tuổi, giới, loại đột biến và loại TKI điều trị.

\section{BÀN LUẬN}

Ung thư phổi không tế bào nhỏ giai đoạn tiến xa có tiên lượng xấu. Những bệnh nhân có đột biến dẫn đường là nhóm bệnh nhân có đáp ứng với điều trị nhắm đích phân tử. Tại Việt Nam cũng như các nước châu Á, đột biến EGFR chiếm tỷ lệ cao [1]. Bệnh nhân có đột biến EGFR có tỷ lệ đáp ứng với các thuốc ức chế Tyrosine Kinase (TKIs) vượt trội so với hóa trị bộ đôi; thời gian sống không tiến triển cũng được nâng lên từ 4-5 tháng lên 9-11 tháng [4]. Các trường hợp tiến triển sau TKIs, nếu có đột biến kháng thuốc T790M thì Osimertinib là lựa chọn ưu tiên. Tuy nhiên, chỉ 50-60\% các trường hợp có đột biến kháng thuốc này [3]. Trong trường hợp không có hoặc không biết tình trạng đột biến T790M, hóa trị bộ đôi được lựa chọn và phác đồ pemetrexed - carboplatin là một lựa chọn trong số đó.

Trong nghiên cứu của chúng tôi, 46 bệnh nhân được điều trị phác đồ pemetrexed carboplatin sau kháng thứ phát với thuốc ức chế Tyrosine Kinase.

Kết quả là có 23 bệnh nhân đáp ứng một phần (chiếm $50,0 \%$ ), có 13 bệnh nhân bệnh ổn định (chiếm 28,3\%), không có bệnh nhẩn nào đạt đáp ứng hoàn toàn, có 10 bệnh nhân bệnh tiếp tục tiến triển (chiếm 21,7\%). Như vậy tỉ lệ đáp ứng khách quan đạt tới $50,0 \%$ và tỉ lệ kiểm soát bệnh trong nghiên cứu là $78,3 \%$. Nếu so sánh kết quả nghiên cứu của chúng tôi với một số kết quả của các tác giả nước ngoài thì kết quả nghiên cứu của chúng tôi cao hơn đáng kể, sự khác biệt này, chúng tôi cho rằng bệnh nhân của chúng tôi là người Việt Nam mà quần thể bệnh nhân châu Á được biết đến là có đáp ứng với hóa chất tốt hơn so với các chủng tộc da trắng [5].

Nghiên cứu AURA3, xét nhánh điêuu trị hóa chất Pemetrexed - Carboplatin có tỉ lệ đáp ứng khách quan là $31 \%$ [3]. Scagliotti và cộng sự (2005) khi so sánh kết quả điều trị của Pemetrexed -Carboplatin đã cho tỷ lệ đáp ứng $31,6 \%$ [6]. Theo Metro G, Chiari R và cộng sự (2011), khi nghiên cứu 80 bệnh nhân cho tỷ lệ đáp ứng khách quan là $42,5 \%$, tỷ lệ kiểm soát bệnh là 77,5\% [7].

Phân tích dưới nhóm cho thấy tình trạng đáp ứng có sự khác biệt có ý nghĩa thống kê đối với các đặc điểm chỉ số toàn trạng $(p=0,043)$, giai đoạn bệnh $(p=0,042)$ và tình trạng có hay không có di cắn hệ thần kinh trung $(p<0,001)$, không có ý nghĩa thống kê đối với các đặc điểm nhóm tuổi, giới, loại đột biến và loại TKI điều trị.

Về sống thêm không tiển triển 2, thời gian trung vị từ lúc hóa trị trong nghiên cứu của chúng tôi đạt 4 tháng (3-6,75 tháng). Kết quả này tương đồng với báo cáo của nghiên cứu AURA3 [3]

\section{KẾT LUÂN}

Nghiên cứu 46 bệnh nhân ung thư phổi không tế bào nhỏ điều trị pemetrexed carboplatin sau kháng thứ phát với EGFR TKIs, chúng tôi rút ra những kết luận sau:

- Tỷ lệ đáp ứng khách quan 50\%; đáp ứng hoàn toàn $0 \%$; kiểm soát bệnh $78,3 \%$

- Các yễu tố tiên lượng đáp ứng kém:

+ Toàn trạng PS1

+ Giai đoạn IV

+ Di căn thân kinh trung ương

- Sống thêm không bệnh tiến triển 2 trung vị: 4 tháng

\section{TÀI LIẸU THAM KHẢO}

1. Anh Thu Huynh Dang, et al (2020). Actionable Mutation Profles of non-Small cell Lung cancer patients from Vietnamese population. Scientific Reports, 10:2707 https://doi.org/10.1038/s41598020-59744-3 5

2. Su KY, Chen HY, Li KC, et al (2012). Pretreatment epidermal growth factor receptor (EGFR) T790M mutation predicts shorter EGFR tyrosine kinase inhibitor response duration in patients with non-small-cell lung cancer. J Clin Oncol, 30(4):433. Epub 2012 Jan 3.

3.Tony S. Mok, Yi-Long Wu, Myung-Ju Ahn, et al (2017). Osimertinib or Platinum-Pemetrexed in EGFR T790M-Positive Lung Cancer. New England journal of Medicine, 376;7, 629-40.

4. Mok TS, Wu YL, Thongprasert S, et al (2009). Gefitinib or carboplatin-paclitaxel in pulmonary adenocarcinoma. N Engl J Med. 361(10):947.

5. Lin C.-C., Hsu H.-H., Sun C.-T. và cộng sự. (2010). Chemotherapy Response in East Asian Non-small Cell Lung Cancer Patients Harboring Wild-Type or Activating Mutation of Epidermal Growth Factor Receptors. J Thorac Oncol, 5(9), 1424-1429

6. Scagliotti G.V. (2005). Pemetrexed plus carboplatin or oxaliplatin in advanced non small cell lung cancer. Semin Oncol, 32(2 Suppl 2), S5-8

7. Metro G., Chiari R., Mare M.et al. (2011). Carboplatin plus pemetrexed for platinum pretreated, advanced non-small cell lung cancer: a retrospective study with pharmacogenetic evaluation. Cancer Chemother Pharmacol, 68(6), 1405-1412. 